\title{
Analisa Pengaruh Perubahan Beban Output Turbin Terhadap Efisiensi Boiler
}

\author{
Jatmiko Edi Siswanto \\ Program Studi, Teknik Mesin, Sekolah Tinggi Teknologi Nasional Jambi (STITEKNAS) - Jambi \\ Jl.Pattimura No. 100 Kota Jambi, Indonesia \\ Correspondence email: jatmikoedis@gmail.com
}

\begin{abstract}
Abstrak. Pada perusahaan pengolahan kelapa sawit hingga menjadi minyak proses perebusan dilakukan untuk memudahkan berondolan dari tandannya, menghentikan perkembangan asam lemak bebas (free faty acid) dan akan menyebabkan tbs melunak sehingga proses ekstraksi minyak menjadi lebih gampang. Proses perebusan membutuhkan uap dari steam, Steam di peroleh dengan memanaskan bejana yang berisi air dengan bahan bakar. Umumnya boiler memakai bahan bakar cair, gas,dan padat. Steam berfungsi sebagai pembangkt listik dan perebusan, pada perusahaan digunakan boiler sebagai producer uap mendukung proses produksi. Boiler atau ketel uap merupakan bejana tertutup yang digunakan untuk menghasilkan uap, melalui proses konversi energi. Untuk mengetahui efisiensi boiler dilakukan perhitungan dengan mengambil parameter yang dibutuhkan pada operasional boiler, dari analisa didapat hasil effisiensi tertinggi ketel adalah 83,56\% dan terendahnya adalah 75,25\% , dimana nilai kalor dengan bahan bakar 13\% pada beban $1000 \mathrm{Kw}$ sebesar 83,56\%. Dan nilai kalor dengan bahan bakar $10 \%$ pada beban 750 $\mathrm{Kw}$ lebih kecil dengan nilai sebesar 75,25\%.
\end{abstract}

Kata Kunci : Boiler, Beban, efisiensi boiler

Abstract. In palm oil processing companies to become oil, the boiling process is carried out to make it easier for the loose fruit to come from the bunches, to stop the development of free fatty acids and will cause the tbs to soften so the oil extraction process becomes easier. The boiling process requires steam from steam. Steam is obtained by heating a vessel filled with water with fuel. Generally, boilers use liquid, gas and solid fuels. Steam functions as a boiling and electric generator, the company uses a boiler as a steam producer to support the production process. A boiler or steam boiler is a closed vessel used to produce steam through an energy conversion process. To find out the boiler efficiency, a calculation is carried out by taking the parameters needed for boiler operation, from the analysis the highest boiler efficiency results are $83.56 \%$ and the lowest is $75.25 \%$, where the heating value with $13 \%$ fuel at $1000 \mathrm{Kw}$ load is $83,56 \%$. And the calorific value with $10 \%$ fuel at a load of $750 \mathrm{Kw}$ is smaller with a value of $75.25 \%$.

Keywords: Boiler, Load, boiler efficiency.

\section{PENDAhULUAN}

Seiring dengan perkembangan zamanpertumbuhan industri - industri di Indonesia sangat pesat, dengan beraneka ragam industri antara lain pabrik karet, pabrik kayu, pabrik makanan dan minuman, pabrik industri khusus dan pabrik kelapa sawit. PT.Perkebunan nusantara VI (persero) adalah salah satu industri yang bergerak dalam bidang pengolahan kelapa sawit. Di perusahaan ini proses pengolahan kelapa sawit dimulai dari tahap perebusan buah sawit, yang berupa Tandan buah segar (TBS) buah sawit dari perkebunan yang baru di panen. Perusahaan yang terkenal dengan pengolahan kelapa sawit hingga menjadi minyak kelapa sawit mentah ini, dalam proses perebusan TBS dipanaskan dengan Uap yang dihasilkan boiler pada temperatur $135^{\circ} \mathrm{C}[1]$.

Proses perebusan dilakukan untuk memudahkan pemimpilan berondolan dari tandannya, menghentikan perkembangan asam lemak bebas (free faty acid) dan akan menyebabkan TBS melunak sehingga proses ekstraksi minyak menjadi lebih gampang. Proses perebusan membutuhkan uap dari steam, Steam di peroleh dengan memanaskan bejana yang berisi air dengan bahan bakar. Umumnya boiler memakai bahan bakar cair, gas,dan padat. Steam berfungsi sebagai pengering Di perusahaan ini, digunakanlah boiler sebagai producer uap untuk mendukung proses produksi. Boiler atau ketel uap merupakan bejana tertutup yang digunakan untuk menghasilkan uap, melalui proses konversi energi. Pada umumnya, uap yang dihasilkan dari boiler dapat digunakan sebagai pembangkit energi utama atau sebagai pendukung proses produksi. Uap sebagai pembangkit energi utama, biasanya dimanfaatkan pada pembangkit tenaga listrik. Sedangkan sebagai pendukung proses produksi, uap digunakan untuk pengering atau pemanas. Di PT. Perkebunan Nusantara VI (persero) uap yang dihasilkan boiler digunakan untuk proses pengkondisian kandungan air pada buah sawit, serta sebagai penyedia air panas.

Proses pengkondisian kelembaban buah sawit dari hasil perebusan, uap yang dihasilkan oleh boiler ditampung dalam sebuah header untuk di distribusikan ke setiap Unit yang membutuhkan uap. uap yang dikonsumsi sesuai dengan proses yang sedang berlangsung. Setelah uap tersebut selesai digunakan, kemudian dikirim ke unit condensate untuk mengubah fasa uap menjadi air. tahapan selanjutnya adalah mengirim air hasil kondensasi tersebut ke unit deaerator 
untuk mengurangi kandungan udara dalam air. Air dari sinilah yang digunakan sebagai feed water pada boiler[2].

Bahan bakar yang digunakan untuk menghasilkan uap berupa fiber dan cangkang.Dari penjelasan diatas, penggunaan uap sebagai pendukung proses produksi serta sebagai pembangkit tenaga listrik.

\section{KAJIAN PUSTAKA}

Pada pabrik kelapa sawit terdapat banyak jenis boiler dengan berbagai bentuk dan ukuran. Karena didalam sebuah pabrik penolahan minyak sawit boiler sama halnya dengan jantung pada manusia.

Boiler adalah salah satu peralatan dari yang berperan sangat penting dalam proses bekerjanya pengolahan minyak kelapa sawit (crude palm oil) funsinya untuk menghasilkan steam (uap)[3].

\section{Siklus Pada boiler}

Siklus Rankine adalah siklus teoritis yang mendasari siklus kerja dari suatu pembangkit daya uap. Siklus Rankine berbeda dengan siklus-siklus udara ditinjau dari fluida kerjanya yang mengalami perubahan fase selama siklus pada saat evaporasi dan kondensasi, oleh karena itu fluida kerja untuk siklus Rankine harus merupakan uap. Siklus Rankine ideal tidak melibatkan beberapa masalah irreversibilitas internal. Irreversibilitas internal dihasilkan

dari gesekanfluida,throttling,danpencampuran,yang paling penting adalah irreversibilitas dalam turbin dan pompa dan kerugian-kerugian tekanan dalam penukar-penukar panas, pipa-pipa, bengkokan-bengkokan, dan katupkatup.Temperatur air sedikit meningkat selama proses kompresi isentropik karena ada penurunan kecil dari volume jenis air, air masuk boiler sebagai cairan kompresi pada kondisi 2 dan meninggalkan boiler sebagai uap kering pada kondisi 3.

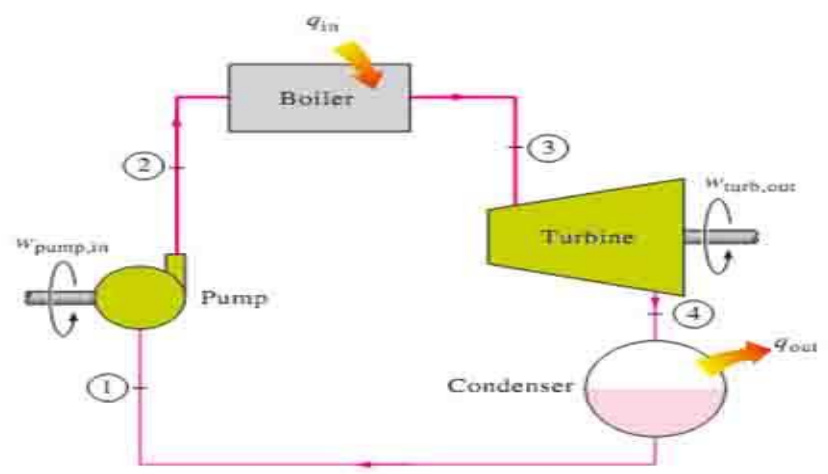

Gambar 1. .Siklus rankine

Boiler pada dasarnya penukar kalor yang besar dimana sumber panas dari pembakaran gas, reaktor nuklir atau sumber yang lain ditransfer secara esensial ke air pada tekanan konstan. Uap superheater pada kondisi ke 3 masuk ke turbin yang mana uap diexpansikan secara isentropik dan menghasilkan kerja oleh putaran poros yang dihubungkan pada generator lisrik.
Temperatur dan tekanan uap jatuh selama proses ini mencapai titik 4, dimana uap masuk ke kondensor dan pada kondisi ini uap biasanya merupakan campuran cairan-uap jenuh dengan kualitas tinggi. Uap dikondensasikan pada tekanan konstan di dalam kondensor yang merupakan alat penukar kalor mengeluarkan panas ke medium pendingin.Uap panas lanjut dari ketel memasuki turbin, setelah melalui beberapa tingkatan sudu turbin, sebagian uap diekstraksikan ke deaerator, sedangkan sisanya masuk ke kondensor dan dikondensasikan didalam kondensor. Selanjutnya air dari kondensor dipompakan ke deaerator juga. Di dalam deaerator, uap yang berasal dari turbin yang berupa uap basah bercampur dengan air yang berasal dari kondensor. Kemudian dari deaerator dipompakan kembali ke ketel, dari ketel ini air yang sudah menjadi uap kering dialirkan kembali lewat turbin. Tujuan uap diekstraksikan ke deaerator adalah untuk membuang gas-gas yang tidak terkondensasi sehingga pemanasan pada ketel dapat berlangsung efektif, mencegah korosi pada ketel, dan meningkatkan efisiensi siklus.Untuk mempermudah penganalisaan siklus termodinamika ini, proses-proses tersebut di atas disederhanakan dalam bentuk diagram dapat dilihat seperti pada gambar 2 sebagai berikut[4].

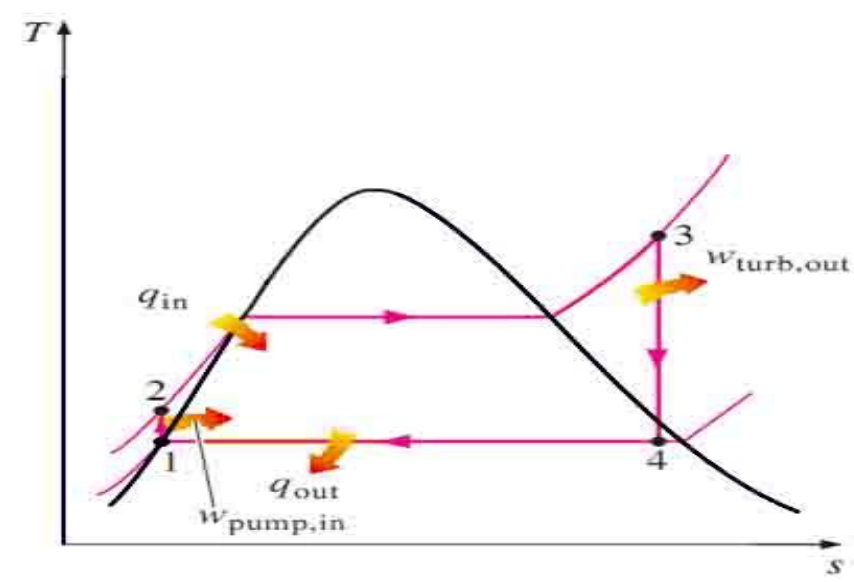

Gambar 2. Diagram T-S siklus Rankine.

\section{Proses Kerja boiler}

Boiler adalah bejana tertutup dimana panas pembakaran dialirkan ke air sampai terbentuk air panas atau steam. Air panas atau steam pada tekanan tertentu kemudian digunakan untuk mengalirkan panas ke suatu proses. Air adalah media yang berguna dan murah untuk mengalirkan panas ke suatu proses. Sistem boiler terdiri dari: sistem air umpan, sistem steam dan sistem bahan bakar. Sistem air umpan menyediakan air untuk boiler secara otomatis sesuai dengan kebutuhan steam. Sistem steam mengumpulkan dan mengontrol produksi steam dalam boiler. Steam dialirkan melalui sistem pemipaan ke titik pengguna. Sistem bahan bakar adalah semua peralatan yang digunakan untuk menyediakan bahan bakar untuk menghasilkan panas yang dibutuhkan. Peralatan yang diperlukan pada sistem bahan bakar 
tergantung pada jenis bahan bakar yang digunakan pada sistem. Air yang disuplai ke boiler untuk dirubah menjadi steam disebut air umpan[4][7]..

Dua sumber air umpan adalah kondensat atau steam yang mengembun yang kembali dari proses dan air makeup (air baku yang sudah diolah) yang harus diumpankan dari luar ruang boiler. Untuk mendapatkan efisiensi boiler yang lebih tinggi, digunakan economizer untuk memanaskan awal air umpan menggunakan limbah panas pada gas buang. Kompenennya terdiri dari:

\section{Furnane (ruang bakar)}

Sebagai tempat pembakaran bahan bakar (fiber dan cangkang) untuk menghasilkan gas panas. Yang memiliki lantai (fire gratee) berupa susunan roster yang dibuka tutup dengan pneumatic zatau model fixed gratee mempunyai lubang-lubang (deashing nozeel) atau tempat lewatnya udara pembakaran dari forced draft fan (Fd fan). Lubang tidak boleh tumpat agar pembakaran dapat sempurna yang dilengkapi "firing door" pada bagian depan yang berfungsi sebagai .

\section{Tube Super Heater}

Berfungsi untuk meningkatkan temperatur uap kering (satured steam) sampai temperatur uap superheat $\left(280^{\circ} \mathrm{C}-300^{\circ} \mathrm{C}\right)$. Tube superheater berisi uap yang berassal dri drum atas lalu dipanaskan gas panas selanjutnya di distribusikan ke header uap untuk seterusnya digunakan oleh turbin. Biasanya berbelokbelok yang mana ujung awal dihubungkan dengan uap drum atas sedang ujungnya berhubungan dengan Header steam

\section{Drum Atas (Upper Drum)}

Fungsi dari drum atas adalah menampung air umpan untuk di distribusikan ke pipa air oembangkit Steam, menampung uap dari pipa pembangkit dan setelah uap dan titik air dipisahkan pada drum selanjutnya uap dialirkan ke header uap untuk di distribusikan ke turbin.Material drum : Biasanya terbuat dari low carbon steel dengan campuran (crome, vanadium,molybdeum)untuk menghindari elongation yang berlebihan.

\section{Header Air Umpan}

Merupakan bejana baja berbentuk silinder dipasang di sekeliling dapur dan dibawah fire grade pada dinding depan boiler.Befungsi untuk menampung air umpan dan selanjutnya di distribusikan ke pipa air pembangkit uap (water wall).

\section{Ekonomiser}

Berfungsi untuk menaikan temperatur air umpan dengan memanfaatkan sisa gas panas yang dialirkan melalui exchanger dan air umpan boiler dialirkan melalui peralatan ini

\section{Header Uap}

Header uap berfungsi sebagai penampung uap dari pada pembangkit uap dan selanjutnya mendistribusikan ke drum uap (drum atas ).Biasanya berbentuk bejana silinder,tetapi ada juga yang berbentuk persegi empat[5][6].

\section{HASIL DAN PEMBAHASAN}

Pada proses pengambilan data dilakukan dengan mengambil data selama tujuh jam beroperasi. Sehingga di dapatkan rata-rata nya dalam satu hari selama tujuh jam. Sehingga mendapaatkan parameter - parameter yang dibutuhkan.

Tabel 1. Data beban 1000 (Kw)

\begin{tabular}{|c|c|c|c|c|c|c|}
\hline No. & $\mathrm{Tu}^{\prime} \mathrm{C}$ & P.har & Ta. 'C & $\begin{array}{l}\text { nibb } \\
\text { kgjjam }\end{array}$ & $\begin{array}{c}\text { ninuap } \\
\text { ton / jam }\end{array}$ & $\begin{array}{c}\text { Persentase } \\
\text { bb\% dari } \\
\text { 45ton }\end{array}$ \\
\hline 1 & $280^{\circ} \mathrm{C}$ & 20 bar & $90^{\circ} \mathrm{C}$ & $30 \mathrm{~kg} j \mathrm{~mm}$ & $\begin{array}{c}18 \\
\text { ton } / \mathrm{iam}\end{array}$ & $14 \%$ \\
\hline 2 & $279^{\circ} \mathrm{C}$ & 2lbar & $89^{\circ} \mathrm{C}$ & $28 \mathrm{kgjam}$ & $\begin{array}{c}19 \\
\text { ton } / \mathrm{jam}\end{array}$ & $13 \%$ \\
\hline 3 & $278^{\circ} \mathrm{C}$ & 20 bar & $88^{\circ} \mathrm{C}$ & $29 \mathrm{kgjam}$ & $\begin{array}{c}18 \\
\mathrm{ton} / \mathrm{jam}\end{array}$ & $14 \%$ \\
\hline 4 & $276^{\circ} \mathrm{C}$ & 19 bar & $85^{\circ} \mathrm{C}$ & $28 k g j a m$ & $\begin{array}{c}\text { Thton ja } \\
\mathrm{m}\end{array}$ & $11 \%$ \\
\hline 5 & $275^{\circ} \mathrm{C}$ & ISbar & $86^{\circ} \mathrm{C}$ & $26 \mathrm{kgjam}$ & $\begin{array}{c}\text { 17ton ja } \\
\text { m }\end{array}$ & $12 \%$ \\
\hline 6 & $274^{\circ} \mathrm{C}$ & 17 bar & $84^{\prime} \mathrm{C}$ & $27 \mathrm{kgjam}$ & $\begin{array}{l}\text { 19ton ja } \\
\text { m }\end{array}$ & $14 \%$ \\
\hline 7 & $273^{\circ} \mathrm{C}$ & 16 bur & $90^{\circ} \mathrm{C}$ & $10 \mathrm{kgjam}$ & $18 t a n$ jm & $13 \%$ \\
\hline $\begin{array}{c}\text { Rata- } \\
\text { rata }\end{array}$ & $276^{\circ} \mathrm{C}$ & 19 bar & $87^{\prime} \mathrm{C}$ & $28 \mathrm{kgjam}$ & 18 toonjm & $13 \%$ \\
\hline
\end{tabular}

\section{Perhitungan Efisiensi Boiler Pada beban 1000 (Kw)}

- Fiber 13\% persentase bahan bakar dari 45 ton

- $13 \%$ x 45 ton $=5800 \mathrm{~kg}$

Komposisi yang terkandung dalam bahan bakar fiber

Dimana komposisi yang terkandung sudah ketetapan.

Water $=39,8 \% \times 5800 \mathrm{~kg}$

$$
\begin{aligned}
\text { NOS } & =55,6 \% \times 5800 \mathrm{~kg} \\
& =3224 \mathrm{~kg} \\
\text { OIL } & =4,56 \% \times 5800 \mathrm{~kg} \\
& =269 \mathrm{~kg}
\end{aligned}
$$

Heating Value

$$
\begin{array}{ll}
\mathrm{NOS} & =3850 \mathrm{Kcal} / \mathrm{Kg} \\
\mathrm{OIL} & =8800 \mathrm{Kcal} / \mathrm{Kg}
\end{array}
$$

Heat Evaporation Water $=600 \mathrm{Kcal} / \mathrm{kg}$

$\eta \mathrm{b}=\frac{\text { Qout }}{\text { Qin }}=\frac{\text { minuap( }(\Delta \mathrm{h})}{\mathrm{mbb}(\mathrm{N} . \mathrm{O})} \times 100 \%$

$\mathrm{N}, \mathrm{O}=($ Nos bb XNos heat value $)+(\mathrm{Oil}$ x oil heat value $)-$

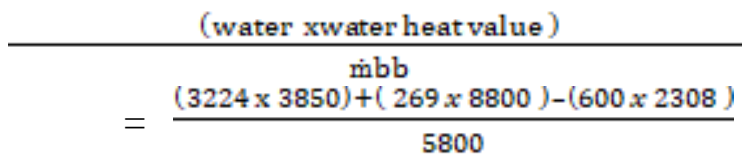

$$
\begin{aligned}
& \text { N.O fiber } \quad=2309 \mathrm{Kcal} / \mathrm{Kg} \\
& \text { Qin } \quad=\dot{\mathrm{mbb} X} \mathrm{~N} . \mathrm{O} \\
& =5800 \mathrm{~kg} / \mathrm{jam} X 2309 \mathrm{kcal} / \mathrm{kg} \\
& =13.392,200 \mathrm{Kcal} / \mathrm{kg} \\
& \text { Qin } \quad=56.070463 \mathrm{kj} / \mathrm{kg} \\
& \text { h1 P }=19 \text { bar }, \mathrm{Tu}=276^{\circ} \mathrm{C}
\end{aligned}
$$


$\begin{array}{ll}\text { Enthalpy } & =2967.57 \mathrm{kj} / \mathrm{kg} \\ \mathrm{h} 2 \text { ta } & =87^{\circ} \mathrm{C} \\ \text { Enthalpy } & =364.352 \mathrm{kj} / \mathrm{kg}\end{array}$

$\rightarrow$ Dapat di cari dengan cara interpolasi menggunakan tabel Properties of saturated water steam.

\begin{tabular}{|c|c|}
\hline Qout & $=($ muap $\times \Delta \mathrm{h})$ \\
\hline & $=18000 \mathrm{~kg} \mathrm{uap} / \mathrm{jam} \times 2.603,218$ \\
\hline Qout & $=4,857,924 \mathrm{kj} / \mathrm{kg}$ \\
\hline$\eta b$ & $=\frac{\text { Qout }}{\text { Qin }} \times 100 \%$ \\
\hline & $\begin{array}{l}=\overline{56.070463}= \\
=83,56 \%\end{array}$ \\
\hline
\end{tabular}

\section{Perhitungan Efisiensi Boiler Pada beban 950 (kw)}

- Fiber $12 \%$ persentase bahan bakar

- $12 \%$ x 45 ton $=5400 \mathrm{~kg}$

Komposisi yang terkandung dalam bahan bakar fiber

Water

$$
\begin{aligned}
& =39,8 \% \text { x } 5400 \mathrm{~kg} \\
& =2149 \mathrm{~kg} \\
& =55,6 \% \times 5400 \mathrm{~kg} \\
& =3002 \mathrm{~kg} \\
& =4,56 \% \times 5400 \mathrm{~kg} \\
& =251 \mathrm{~kg}
\end{aligned}
$$$$
\text { NOS } \quad=55,6 \% \times 5400 \mathrm{~kg}
$$$$
\text { OIL } \quad=4,56 \% \times 5400 \mathrm{~kg}
$$

\section{Heating Value \\ NOS $\quad=3850 \mathrm{Kcal} / \mathrm{Kg}$ \\ OIL $\quad=8800 \mathrm{Kcal} / \mathrm{Kg}$}

Heat Evaporation Water $=600 \mathrm{Kcal} / \mathrm{kg}$

$\eta \mathrm{b}=\frac{\text { Qout }}{\text { Qin }}=\frac{\text { nhuap }(\Delta \mathrm{h})}{\text { minb }(\mathrm{N} . \mathrm{O})} \times 100 \%$

N. $\mathrm{O}=($ Nos bbX Nos heat value $)+($ Oil $\mathrm{x}$ oil heat value $)-$

(water xwater heatvalue)

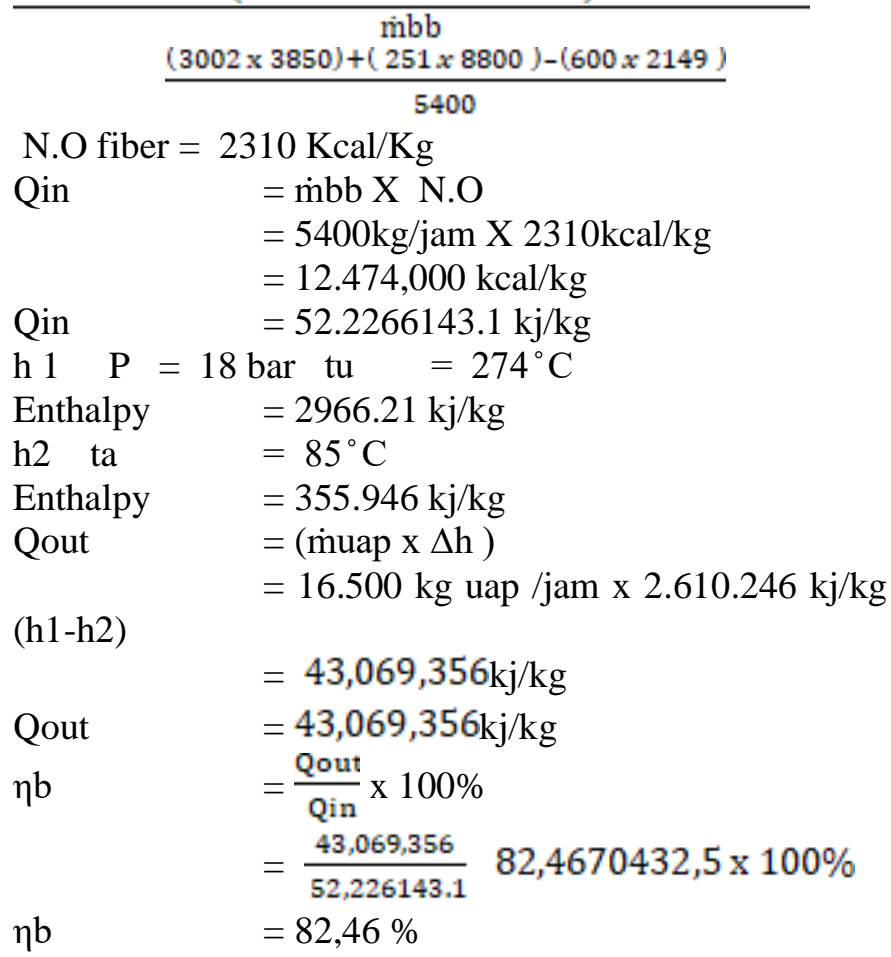

Perhitungan efisiensi Beban 850 (Kw)

- Fiber $11 \%$ persentase bahan bakar
$-11 \% \times 45$ ton $=4900 \mathrm{~kg}$

Komposisi yang terkandung dalam bahan bakar fiber

Water $=39,8 \%$ x $4900 \mathrm{~kg}$

NOS $\quad=55,6 \% \times 4900 \mathrm{~kg}$

$=2724 \mathrm{~kg}$

OIL $\quad=4,56 \% \times 4900 \mathrm{~kg}$ $=227 \mathrm{~kg}$

Heating Value

NOS $\quad=3850 \mathrm{Kcal} / \mathrm{Kg}$

OIL $\quad=8800 \mathrm{Kcal} / \mathrm{Kg}$

Heat Evaporation Water $=600 \mathrm{Kcal} / \mathrm{kg}$

$\eta \mathrm{b}=\frac{\text { Qout }}{\mathrm{Qin}}=\frac{\text { muap( }(\Delta \mathrm{h})}{\operatorname{mbb}(\mathrm{N} . \mathrm{O})} \times 100 \%$

N.O $=($ Nos bbXNos heat walue $)+($ Oil, bb x oil heat walue $)$ -(water.bb water heat walue) m̊bb

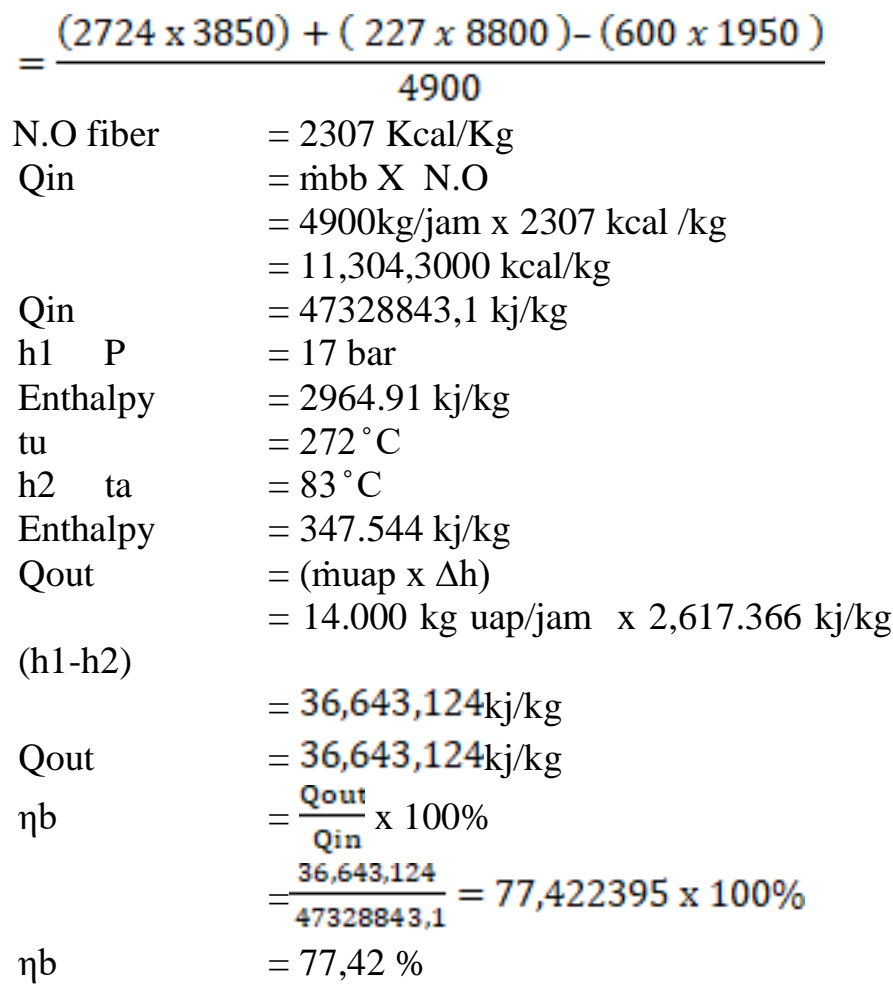

\section{Perhitungan efisiensi Beban 750 ( Kw)}

- Fiber $10 \%$ persentase bahan bakar

- $10 \%$ x 45 ton $=4500 \mathrm{~kg}$

Komposisi yang terkandung dalam bahan bakar fiber

Water $=39,8 \%$ x $4500 \mathrm{~kg}$

NOS $\quad=55,6 \% \times 4500 \mathrm{~kg}$

$\begin{aligned} & =2502 \mathrm{~kg} \\ \text { OIL } & =4,56 \% \times 4500 \mathrm{~kg}\end{aligned}$

$$
=209 \mathrm{~kg}
$$

Heating Value $\mathrm{NOS}=3850 \mathrm{Kcal} / \mathrm{Kg}$

OIL $\quad=8800 \mathrm{Kcal} / \mathrm{Kg}$

Heat Evaporation Water $=600 \mathrm{Kcal} / \mathrm{kg}$

$\eta \mathrm{b}=\frac{\text { Qout }}{\text { Qin }}=\frac{\text { muap }(\Delta \mathrm{h})}{\text { mbb(N.O) }} \times 100 \%$ 


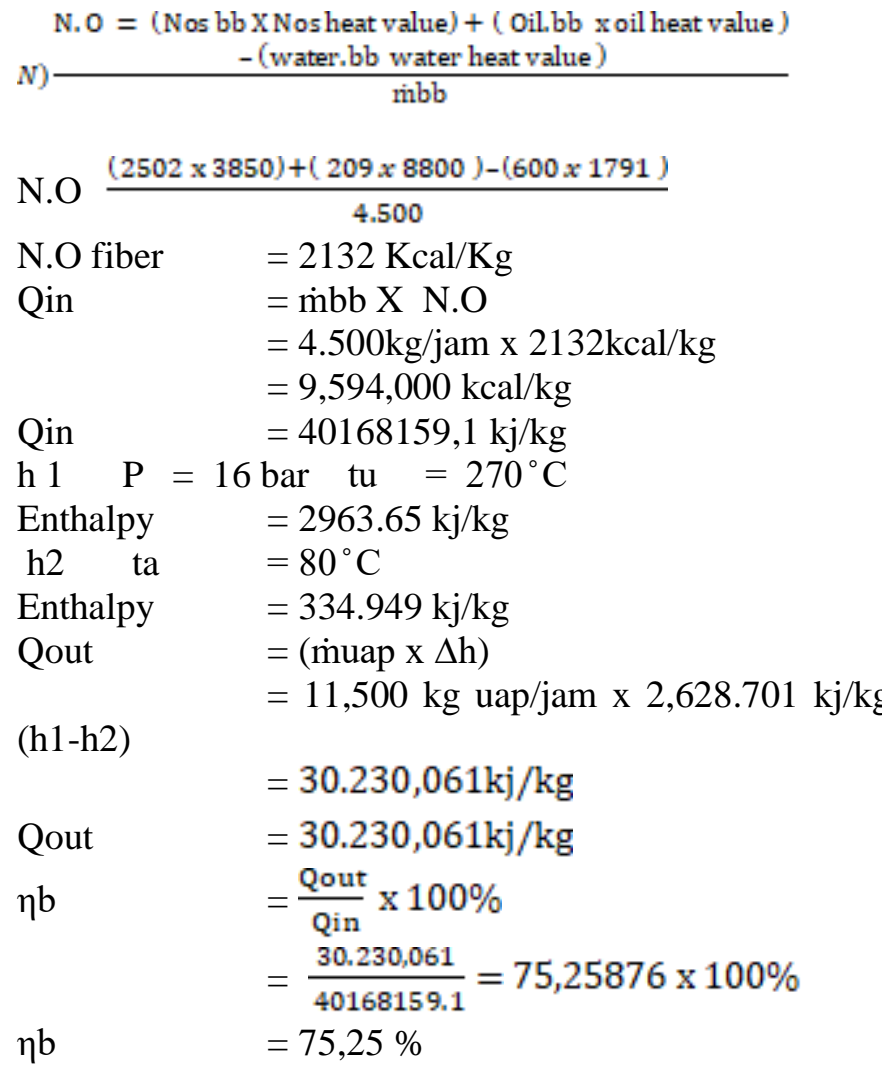

\section{Analisa Grafik}

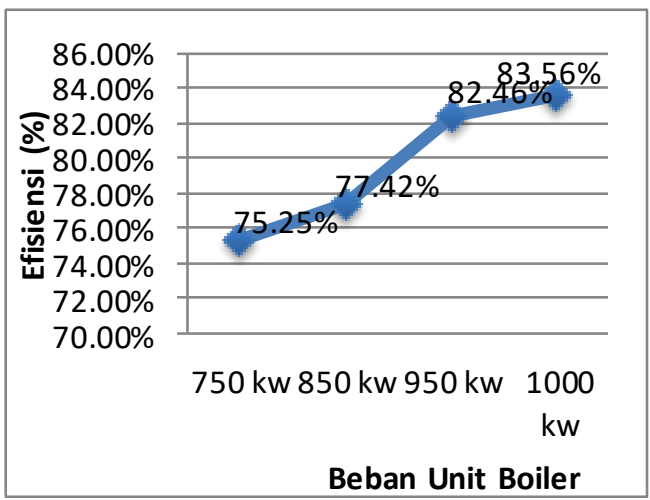

Gambar 3. Grafik perbandingan efisiensi pada masingmasing beban

Dari grafik diatas dapat di ketahui, bahwa efisiensi terendah boiler terdapat pada beban $750 \mathrm{Kw}$ dengan nilai $75,25 \%$ ini dikarekan persentase bahan bakar boiler pada beban $750 \mathrm{Kw}$ adalah 10\% dari 45ton kapasitas. Maka nilai kalor dengan bahan bakar $10 \%$ pada beban $750 \mathrm{kw}$ lebih kecil sehingga efisiensi pada beban ini hanya $75,25 \%$. Sedangkan efisiensi tertinggi boiler adalah terdapat pada beban $1000 \mathrm{Kw}$ dengan nilai 83,56\% ini dikarenakan persentase bahan bakar boiler pada beban $1000 \mathrm{Kw}$ adalah $13 \%$ dari 45ton kapasitas. Maka nilai kalor dengan bahan bakar 13\% pada beban $1000 \mathrm{Kw}$ lebih tinggi sehingga efisiensi pada beban ini lebih tinggi dengan nilai $83,56 \%$.

\section{KESIMPULAN}

a. Bahwa efisiensi terendah boiler terdapat pada beban $750 \mathrm{Kw}$ dengan nilai $75,25 \%$ ini dikarekan persentase bahan bakar boiler pada beban $750 \mathrm{kw}$ adalah $10 \%$ dari 45ton kapasitas. Maka nilai kalor dengan bahan bakar 10\% pada beban $750 \mathrm{Kw}$ lebih kecil sehingga efisiensi pada beban ini hanya $75,25 \%$.

b. Sedangkan efisiensi tertinggi boiler adalah terdapat pada beban $1000 \mathrm{Kw}$ dengan nilai 83,56\% ini dikarenakan persentase bahan bakar boiler pada beban 1,7MW adalah 13\% dari 45ton kapasitas. Maka nilai kalor dengan bahan bakar $13 \%$ pada beban $1000 \mathrm{Kw}$ lebih tinggi sehingga efisiensi pada beban ini lebih tinggi dengan nilai $83,56 \%$.

\section{Saran}

1. Pentingnya perawatan yang rutin dilakukan untuk menjaga agar boiler beroperasi dengan baik.

2. Rutin melakukan pengecekan pipa-pipapada boiler, membersihkan kerak-kerak yang menempel

\section{DAFTAR PUSTAKA}

[1] Putra Is Dewata. 11 Januari 2011. Analisa Teknis Evaluasi Kinerja Boiler Type ihifwsr Single Drum Akibat Kehilangan Panas dipltu pt. PJB unit

[2] Andalas Stell, Petunjuk Pengoperasian boiler, Takuma water tube boiler, oil palm Wastes Firing Boiler

[3] Asmudi. 12 Januar 2010. Analisa Unjuk Kerja Boiler Terhadap Penurunan Daya Pada Pltu PT. Indonesia Power Ubp Perak. Fakultas Teknologi Kelautan, ITS Surabaya.

[4] Budiarjo,IMade Kartika D, Budiars(Penerjemah), 1989. Buku Teks Termodinamika Terpakai, Teknik Uap Dan Panas.Universitas Indonesia.

[5] Syamsir A. Muin, Pesawat-pesawat konversi 1(KetelUap) 1988).

[6] Bandi parapak. 15 Maret 2010 Perekayasaan Ketel Uap Utilitas Pabrik Elemen Bakar Nuklir Tipe

[7] M.Sitorus,.Proses Pengolahan Air Umpan Ketel.,2002.Medan 